\title{
Components of antenatal care received by women in fishing communities on Lake Victoria, Uganda; a cross sectional survey
}

Ali Ssetaala ${ }^{1,2^{*}} \mathbb{D}$, Joan Nabawanuka', Gideon Matovu', Nusula Nakiragga', Judith Namugga', Phiona Nalubega', Henry Lutalo Kaluuma', Kundai Chinyenze ${ }^{3}$, Katrina Perehudoff ${ }^{2}$, Kristien Michielsen², Bernard Bagaya ${ }^{4}$, Matt Price $^{3,5}$, Noah Kiwanuka ${ }^{4}$ and Olivier Degomme ${ }^{2}$

\begin{abstract}
Background: Uganda has one of the highest maternal deaths at a ratio of 336 per 100,000 live births. As Uganda strives to achieve sustainable development goals, appropriate antenatal care is key to reduction of maternal mortality. We explored women's reported receipt of seven of the Uganda guidelines components of antenatal care, and associated factors in hard to reach Lake Victoria island fishing communities of Kalangala district.

Methods: A cross sectional survey among 486 consenting women aged 15-49 years, who were pregnant at any time in the past 6 months was conducted in 6 island fishing communities of Kalangala district, Uganda, during January-May 2018. Interviewer administered questionnaires, were used to collect data on socio-demographics and receipt of seven of the Uganda guidelines components of antenatal care. Regression modeling was used to determine factors associated with receipt of all seven components.

Results: Over three fifths (65.0\%) had at least one ANC visit during current or most recent pregnancy. Fewer than a quarter of women who reported attending care at least four times received all seven ANC components [(23.6\%), $P<0.05]$. Women who reported receipt of ANC from the mainland were twice as likely to have received all seven components as those who received care from islands ( $\mathrm{aOR}=1.8 ; 95 \% \mathrm{Cl}: 0.9-3.7)$. Receipt of care from a doctor was associated with thrice likelihood of receiving all components relative to ANC by a midwife or nurse $(a \mathrm{OR}=3.2 ; 95 \%$ Cl:1.1-9.1).
\end{abstract}

Conclusions: We observed that the delivery of antenatal care components per Ugandan guidelines is poor in these communities. Cost effective endeavors to improve components of antenatal care received by women are urgently needed. Task shifting some components of ANC to community health workers may improve care in these island communities.

Trial registration: PACTR201903906459874 (Retrospectively registered).

Keywords: Antenatal, care, Components, Women, Islands, Fishing, Community, Uganda

\footnotetext{
*Correspondence: assetaala@iavi.or.ug; Ali.Ssetaala@UGent.be

'UVRI-IAVI HIV Vaccine Program, Entebbe, Uganda

${ }^{2}$ Ghent University International Centre for Reproductive Health, Ghent,

Belgium

Full list of author information is available at the end of the article
}

(C) The Author(s). 2020 Open Access This article is licensed under a Creative Commons Attribution 4.0 International License, which permits use, sharing, adaptation, distribution and reproduction in any medium or format, as long as you give appropriate credit to the original author(s) and the source, provide a link to the Creative Commons licence, and indicate if changes were made. The images or other third party material in this article are included in the article's Creative Commons licence, unless indicated otherwise in a credit line to the material. If material is not included in the article's Creative Commons licence and your intended use is not permitted by statutory regulation or exceeds the permitted use, you will need to obtain permission directly from the copyright holder. To view a copy of this licence, visit http://creativecommons.org/licenses/by/4.0/ The Creative Commons Public Domain Dedication waiver (http://creativecommons.org/publicdomain/zero/1.0/) applies to the data made available in this article, unless otherwise stated in a credit line to the data. 


\section{Background}

Uganda has one of the highest maternal deaths with a mortality ratio of 336 per 100,000 live births, mostly in FormattingCitation\} rural, resource limited, hard-toreach settings [1]. Maternal deaths are often from hemorrhage, hypertension, sepsis, unsafe abortions and other indirect causes like malnutrition, HIV, malaria, poor utilization of health services, poor quality care, critical shortages of skilled attendants and socio-cultural, economic factors [2-4].

Components of antenatal care (ANC), involving investigations and interventions by a Midwife, Nurse or Doctor on a pregnant woman are important in averting maternal deaths $[5,6]$. The current Uganda clinical guidelines recommend at least four goal oriented ANC visits, far below the current WHO recommendations of at least eight contacts for a positive pregnancy experience and reduction of perinatal mortality [7, 8]. The ANC visits should provide components of care that include blood pressure measurement, fetal growth monitoring, urine testing, iron-folic acid supplementation, tetanus vaccination, at least three doses of Intermittent Preventive Treatment with Sulphadoxine/pyrimethamine (IPTp), deworming after the first trimester, blood group typing if not done previously, HIV and syphilis testing [7]. The 2016 Uganda demographic and Health survey indicates that almost all women from island communities with a childbirth during the preceding 5 years, had at least one ANC visit [1]. However, ANC visits attendance per se doesn't directly translate into receipt of care components, yet these impact on the quality process, affecting subsequent visits, cost of care, skilled birth attendance and eventual prevention of maternal-child deaths [9-12].

Per the Avedis Donabedian model for quality of care [13], ANC components may be an important element in assessing quality, especially in situations where there is a barely adequate availability of structural inputs. Blood pressure measurement aids the diagnosis, prevention, and management of hypertensive conditions of pregnancy including chronic hypertension, gestational hypertension, preeclampsia, eclampsia, and preeclampsia superimposed on chronic hypertension [14]. Urine testing is key in the early diagnosis, prevention and management of urinary tract infections, gestational diabetes, preterm labor, low birth weight and pre-eclampsia [14, 15]. Urine testing also facilitates decisions to start ANC through early diagnosis of pregnancy [16]. ANC tetanus vaccination injections help prevent the fatal tetanus among women and their babies. Blood sample provision helps in screening and prompt management of anemia which can lead to low birth weight and maternal mortality [17]. Maternal infections detrimental to the woman and her unborn baby like malaria, hepatitis B, syphilis,
HIV, gonorrhea and chlamydia are identified early during pregnancy through provision of a blood sample [1822]. HIV testing during antenatal care, often done through blood samples is an entry point to elimination of mother to child HIV transmission (eMTCT), prevention and treatment for the partner and community at large. Provision of deworming treatment helps treat maternal infections that also have effects on the unborn baby, especially in helminths endemic areas [23]. Iron and folic acid supplementation is key in preventing anemia, including adverse effects of postpartum hemorrhage, preterm births and low birth weight babies [24]. Some components of ANC like counseling help improve early initiation of exclusive breast feeding, uptake of childhood immunization and attendance of postnatal care.

Women in hard to reach geographically isolated locations like island fishing communities (FCs) on Lake Victoria, may be at increased risk of maternal death due to inadequate or no provision of care components during ANC visits [25]. These island fishing communities are considered.

hard to reach, resource limited settings, due to maritime challenges and rural location.

Kalangala district has 64 habitable islands FCs with only 17 health facilities (mainly level II and III) serving these islands, of which none is a hospital [26]. There is poor geographic accessibility across one island to another with a health facility, often the nearest health facility being $8-12 \mathrm{~km}$ away. The cost of transporting a mother who needs ANC and delivery is about 55 US dollars, which includes hiring a boat with an engine, a coxswain and buying fuel for the trip [27]. Kalangala district also has a shortage of skilled birth attendants (Doctor, Nurse and Midwife), with only 16.4 skilled birth attendants per 10,000 people, still far below WHO target for sustainable development [26, 28, 29].

We assessed the components of care received by women in these island fishing communities, to inform antenatal care services provision among these hard to reach settings.

\section{Methods}

\section{Study design aim and setting}

This community based cross-sectional survey aimed at characterizing components of care received by ANC attendees living in 6 rural islands (Buwuvu, Jaana, Kitobo, Lulamba, Namisoke and Sserinya) of Kalangala district, Uganda. The islands were selected from 12 islands where the authors had previous research experience based on remoteness (inaccessibility), with the nearest being $2 \mathrm{~h}$ by motorized boat ride from Entebbe mainland and having a population of at least 1000 people [29]. The survey was conducted during January-May 2018, using a 
questionnaire developed for this study with questions from DHS Program surveys [30]. See questionnaire under supplementary material. Further details of the methods are described elsewhere [31].

Women who attended ANC were asked if they received the following seven components of ANC at least once: 1) blood pressure measurement, 2) provision of a blood sample, 3) provision of a urine sample, 4) tetanus vaccination, 5) IPTp including number of times, 6) deworming treatment, and 7) iron-folic acid supplements.

We did not ask women about receipt of any form of counseling. Women were also not asked how many times they received each ANC component, or at what months of pregnancy or with which type of health worker or at what health facility.

\section{Statistical methods}

This analysis aimed at answering the following questions;

1. What proportion of women who attended care received all seven components as part of the Uganda guidelines goal-oriented ANC protocol?

2. What factors are associated with receipt of all seven components of care among women who attended ANC?

\section{Study variables}

The dependent variable was receipt of all seven ANC components by women who attended care during the most recent or current pregnancy. Receipt of all ANC components was generated as a binary outcome with "No, all ANC components" for women who did not receive all seven components at least once and "Yes, all ANC components" for women who received all seven components at least once.

The independent variables included; age, tribal affiliation, highest education attained, women's occupation, partner occupation, total births by a woman, reported pregnancy status at interview, timing of first ANC visit, ANC facility location (island vs mainland), provider cadre and visits attended (less than four or at least four). Frequency tabulation of women's characteristics by receipt of all ANC components was used to analyze the distribution of study related factors and relationships with the dependent variable. Grouping of independent variables was based on their logical relationship with the dependent variable (receipt of all seven ANC components) at bivariable analysis. Bivariable chi-square tests were used to assess the associations between independent variables and the dependent variable at $95 \%$ significance level.

Multivariable logistic regression modeling was used to determine participant characteristics associated with receipt of all ANC components by women who attended ANC at least once. Selection of predictor variables included for the multivariable model was based on previous literature, biological plausibility or statistical significance $(P$-value $\leq 0.2)$ at bivariable analysis. We selected a priori women's age (binary), occupation (binary), ethnicity (binary), duration of stay in study community (binary), total births (categorical), number of ANC times (counts), cadre of ANC provider (binary) and location of ANC service (binary) as independent variables for the multivariable model. We assessed for collinearity and removed variables that did not improve the model or were highly correlated with other variables in the model, with the final best suited predictors in the model having the lowest $P$-values (up to $p=0.05$ ), lowest model Akaike's information criterion (AIC) and Bayesian information criterion (BIC) values. Adjusted Odds ratios (aOR), $P$-values and 95\% confidence intervals (CI) were used to report associations. All analyses were done using STATA $^{\bullet}$ version 15.1 [32]. Tables were created using asdoc [33].

\section{Results}

\section{Participants characteristics}

The survey involved 486 women from 6 island FCs and was conducted between January and May 2018, 246 (50.6\%) of whom were currently pregnant and 240 (49.4\%) were not currently pregnant but had been within the past 6 months. Women's age ranged between 15 to 45 years, majority were married (87.0\%), their main occupation was housewife (stay-at-home mums) $(45.1 \%)$ and never studied beyond 7 years of education (69.1\%). See Table 1.

Total pregnancies by each woman ranged from 1 to 11 , a third $(32.9 \%)$ had five or more. Median parity was 3 , ranging from 0 to 11 , with nearly a third (31.5\%) having at least four births.

All 486 women reported they would have liked being attended to by a skilled ANC provider during current or recent pregnancy. Over three fifths $(65.0 \%)$ had at least one ANC visit during current or most recent pregnancy, with majority $(62.7 \%)$ starting late after the first trimester (mean/SD months at start $=3.96 / 1.65)$ and attending from island-based health facilities (78.2\%). See Table 1.

\section{Components of ANC}

Less than one in five women who attended at least one visit received all seven assessed ANC components (18.4\%). Nearly all women received at least one component $(99.7 \%)$, with almost a third $(28.5 \%)$ and two fifths $(36.1 \%)$ receiving five and six components respectively. The most common ANC component received was iron supplementation with the least common being urine checks. Among women who had received three ANC components, they were often iron supplementation, blood check and tetanus vaccination injection. See Table 1. 
Table 1 Characteristics of participating women

\begin{tabular}{|c|c|c|}
\hline Characteristics & Frequency & Percentage \\
\hline Age groups (Years) & $(n=486)$ & \\
\hline $15-24$ & 193 & 39.7 \\
\hline $25-49$ & 293 & 60.3 \\
\hline Age at first pregnancy (Years) & $(n=486)$ & \\
\hline$<15$ & 52 & 10.7 \\
\hline $15-19$ & 350 & 72.0 \\
\hline$\geq 20$ & 84 & 17.3 \\
\hline Marital status & $(n=486)$ & \\
\hline Married & 423 & 87.0 \\
\hline Not married & 63 & 13.0 \\
\hline Tribal affiliation & $(n=486)$ & \\
\hline None Baganda & 276 & 56.8 \\
\hline Baganda & 210 & 43.2 \\
\hline Highest education completed (Years) & $(n=486)$ & \\
\hline$\geq 8$ (8th grade and above) & 150 & 30.9 \\
\hline 1-7 (up to 7th grade) & 304 & 62.5 \\
\hline 0 (None) & 32 & 6.6 \\
\hline Occupation group & $(n=486)$ & \\
\hline Agriculture & 43 & 8.9 \\
\hline Housewife & 219 & 45.1 \\
\hline Bar, Restaurant, lodge worker/owner & 58 & 11.9 \\
\hline Fishing related & 42 & 8.6 \\
\hline Others & 124 & 25.5 \\
\hline Partner occupation & $(n=423)$ & \\
\hline Fishing related & 299 & 70.7 \\
\hline None fishing related & 124 & 29.3 \\
\hline Duration of community stay & $(n=486)$ & \\
\hline 3-11 months & 94 & 19.3 \\
\hline$\geq 1$ year & 392 & 80.7 \\
\hline Total births (median $=3$, range $0-11$ ) & $(n=486)$ & \\
\hline None & 46 & 9.5 \\
\hline $1-3$ & 287 & 59.0 \\
\hline$\geq 4$ & 153 & 31.5 \\
\hline Any ANC attendance & $(n=486)$ & \\
\hline No attendance & 170 & 35.0 \\
\hline Attended & 316 & 65.0 \\
\hline First ANC visit timing & $(n=316)$ & \\
\hline$\leq 3$ months pregnant & 118 & 37.3 \\
\hline$>3$ months pregnant & 198 & 62.7 \\
\hline ANC provider & $(n=316)$ & \\
\hline Nurse/Midwife & 296 & 93.7 \\
\hline Doctor & 20 & 6.3 \\
\hline ANC location & $(n=316)$ & \\
\hline Islands & 247 & 78.2 \\
\hline
\end{tabular}

Table 1 Characteristics of participating women (Continued)

\begin{tabular}{lll}
\hline Characteristics & Frequency & Percentage \\
\hline Mainland & 69 & 21.8 \\
ANC components received (median =6) & $(n=316)$ & \\
Iron supplementation & 308 & 97.5 \\
Blood sample & 281 & 88.9 \\
T.T injection & 275 & 87.0 \\
Blood pressure measured & 266 & 84.2 \\
IPTp & 261 & 82.6 \\
Deworming & 222 & 70.3 \\
Urine sample & 106 & 33.5 \\
Last HIV test period & $(n=486)$ & \\
Within 3 months & 302 & 62.1 \\
Over 3 months & 127 & 26.1 \\
Never tested in life & 1 & 0.2 \\
On ART & 56 & 11.5 \\
Received all seven ANC components & $(n=316)$ & \\
No & 258 & 82.0 \\
Yes & 58 & 18.4 \\
\hline
\end{tabular}

Even among those who reported attending four or more ANC visits, few (23.6\%) received all the seven components of ANC. Just a fifth (20.3\%) of women who started care early within the first 3 months of pregnancy received all ANC components. See Table 2. More women aged 25-49 years received all ANC components relative to those aged $15-24$ years at the time of the survey $(22.0 \%$ vs $12.8 \%, P<$ 0.05). More ANC attendees affiliated to the Baganda tribe received all care components compared to none-Baganda $(23.7 \%$ vs $13.6 \%, P<0.05)$. Fewer stay-at-home mums (Housewives) received all ANC components compared to those who were not stay-at-home moms (13.4\% vs $22.8 \%$, $P<0.05)$. Pregnancy status at the time of the interview was not associated with receipt of all the seven ANC components (currently pregnant [13.5\%], birth within 6 months [22.6\%], abortion or miscarriage within 6 months [13.6\%], $p=0.11$ ). A higher proportion of women who attended ANC from mainland-based facilities received all care components relative to those who attended islandsbased health facilities $(27.5 \%$ vs $15.8 \%, P<0.05)$. Relative to those who received care from Nurses or Midwives, more women attended to by Doctors received all ANC components $(16.6 \%$ vs $45.0 \%, P<0.05)$. See Table 2 .

In our multivariable modeling, we found that women who attended care from mainland facilities were twice as likely to have received all ANC components as those who received care from island facilities $(\mathrm{aOR}=1.8 ; 95 \%$ CI:0.9-3.7). Women who reported being attended to by a Doctor were thrice as likely to have received all ANC components as those seen by a Midwife/Nurse $(\mathrm{aOR}=$ 3.2; 95\% CI:1.1-9.1). The number of times women 
Table 2 ANC attendees' characteristics by components receipt $(n=316)$

\begin{tabular}{|c|c|c|c|}
\hline Characteristics & $\begin{array}{l}\text { Did not receive all ANC components } \\
\text { n (\%) }\end{array}$ & $\begin{array}{l}\text { Received all ANC components } \\
\text { n (\%) }\end{array}$ & $\begin{array}{l}P \text { - } \\
\text { value }\end{array}$ \\
\hline Age groups & & & $<0.05$ \\
\hline $15-24$ & $109(87.2)$ & $16(12.8)$ & \\
\hline $25-49$ & $149(78.0)$ & $42(22.0)$ & \\
\hline Highest education completed (Years) & & & 0.65 \\
\hline 0 (None) & $18(85.7)$ & $3(14.3)$ & \\
\hline $1-7$ (1st-7th grade) & $163(82.7)$ & $34(17.3)$ & \\
\hline$\geq 8$ (8th grade and above) & 77 (78.6) & $21(21.4)$ & \\
\hline Tribal affiliation & & & $<0.05$ \\
\hline None Baganda & $153(86.4)$ & $24(13.6)$ & \\
\hline Baganda & $105(75.5)$ & $34(24.5)$ & \\
\hline Occupation & & & $<0.05$ \\
\hline Housewife & $129(86.6)$ & $20(13.4)$ & \\
\hline None-Housewife & $129(77.3)$ & $38(22.7)$ & \\
\hline Partner occupation & $(n=277)$ & & 0.07 \\
\hline Fishing related & $162(84.4)$ & $30(15.6)$ & \\
\hline None Fishing related & $64(75.3)$ & $21(24.7)$ & \\
\hline Pregnancy status at interview & & & 0.11 \\
\hline Childbirth within 6 months & $130(77.4)$ & $38(22.6)$ & \\
\hline Currently pregnant & $109(86.5)$ & $17(13.5)$ & \\
\hline Loss pregnancy within 6 months & 19 (86.4) & $3(13.6)$ & \\
\hline ANC location & & & $<0.05$ \\
\hline Islands & $208(84.2)$ & $39(15.8)$ & \\
\hline Mainland & $50(72.5)$ & $19(27.5)$ & \\
\hline ANC provider & & & $<0.05$ \\
\hline Nurse/Midwife & $247(83.4)$ & 49 (16.6) & \\
\hline Doctor & $11(55.0)$ & $9(45.0)$ & \\
\hline First ANC visit timing & & & 0.48 \\
\hline$\leq 3$ months pregnant & $94(79.7)$ & $24(20.3)$ & \\
\hline$>3$ months pregnant & $164(82.8)$ & $34(17.2)$ & \\
\hline ANC visits attended & & & $<0.05$ \\
\hline$<$ Four & $151(85.8)$ & $25(14.2)$ & \\
\hline$\geq$ Four & $107(76.4)$ & $33(23.6)$ & \\
\hline Total births & & & 0.10 \\
\hline None & $25(96.2)$ & $1(3.8)$ & \\
\hline $1-3$ & $145(79.2)$ & $38(20.8)$ & \\
\hline$\geq 4$ & $88(82.2)$ & $19(17.8)$ & \\
\hline
\end{tabular}

attended ANC was associated with likelihood of having received all components of care $(\mathrm{aOR}=1.3,95 \% \mathrm{CI}$ : $1.1-$ 1.5). Older women were more likely to have received all seven components compared to younger women (ages $25+$ compared to $<25$ years, $\mathrm{aOR}=2.0,95 \% \mathrm{CI}: 1.0-3.9$ ), and Baganda tribe was also associated with increased odds of receiving the full package. See Table 3 .

\section{Discussion}

Proper ANC is key to improving reproductive health, increasing skilled birth attendance, reducing maternal morbidity and mortality. We observed that women who attend ANC clinics often did not receive the recommended components of care, with only $18.4 \%$ of those who attended at least once reporting receiving all seven 
Table 3 Crude (COR) and adjusted odds ratios (aOR) of factors associated with all ANC components receipt among clinic attendees ( $n=316)$

\begin{tabular}{|c|c|c|c|c|}
\hline All components receipt & cOR & [95\% Conf.Interval] & aOR & [95\% Conf.Interval] \\
\hline \multicolumn{5}{|l|}{ ANC provider } \\
\hline Nurse/Midwife & (ref) & & (ref) & \\
\hline Doctor & 4.1 & 1.610 .5 & 3.2 & 1.19 .1 \\
\hline ANC times & 1.3 & 1.11 .5 & 1.3 & 1.11 .5 \\
\hline \multicolumn{5}{|l|}{ ANC location } \\
\hline Island & (ref) & & (ref) & \\
\hline Mainland & 2.0 & 1.13 .8 & 1.8 & 0.93 .7 \\
\hline \multicolumn{5}{|l|}{ Tribal affiliation } \\
\hline Non-Baganda & (ref) & & (ref) & \\
\hline Baganda & 2.0 & 1.23 .7 & 2.1 & 1.13 .8 \\
\hline \multicolumn{5}{|l|}{ Age group (Years) } \\
\hline $15-24$ & (ref) & & (ref) & \\
\hline $25-49$ & 1.9 & 1.03 .6 & 2.0 & 1.03 .9 \\
\hline
\end{tabular}

assessed components as by Ugandan government guidelines [7]. Less than a quarter of women who managed to attend four visits did not receive all seven components at least once. Whilst many women attended ANC at least once or four times, comparatively fewer women received all seven ANC components during those visits. This highlights the need to emphasize and assess receipt of components of care during routine monitoring of ANC quality processes in these communities.

Notwithstanding efforts encouraging pregnant women to start ANC early, a large proportion of those who started within the first 3 months of pregnancy did not receive all components, yet it is expected they receive all earlier during ANC attendance [7]. This dampens efforts towards improving maternal health as opportunities to identify, prevent and manage complications through receipt of all ANC components are missed. HIV burden is high in these FCs [34], eMTCT including other early treatment and care interventions are likely to be less effective when started late in pregnancy.

An important public health finding in these island FCs is that mainland health facilities provided more complete ANC relative to those on the islands. Islands are rural and hard to reach, which may impact on the quality of $\mathrm{ANC}$, as supplies and equipment might have been inadequate or lacking $[2,35]$. Though unlikely, skilled attendants might have not provided these components of care despite the equipment and supplies being available due to lack of motivation or heavy workload. We did not assess availability of supplies or workload of staff at the facilities where women received ANC. Island based facilities are also more likely to employ poorly skilled ANC attendants, as few highly skilled health workers want to work in these hard-to-reach, rural FCs. All our study participants were residents of remote islands, and women who attended ANC from mainland health facilities might have had better access to maternal health information and financial means to seek all components of care at facilities where they were easily provided. This adds to previous work on rural-urban ANC differences, uniquely highlighting differences between mainland and islands FCs [36-38].

The cadre of skilled attendant was associated with receipt of all seven ANC components, as women who reported seeing a Doctor were likely to have received all care components relative to those who received care from Nurses or Midwives. Similar to previous work in other settings [39], skilled attendants have a big role during $\mathrm{ANC}$ in these communities.

Attendance of more visits was associated with a higher likelihood of receiving all seven ANC components, as others have observed [40, 41]. Women who attend more visits increase chances of receiving components that were missed during the preceding visits, especially if the lack of receipt was due to stock outs of supplies or faulty equipment that would be later repaired. Women 25 years or older were more likely to have received all ANC components than their younger counterparts, perhaps as they had prior experiences with the health care system and might have known the importance of receiving all components of care. This adds to similar to work in India [42], were older women received more adequate care than adolescents.

Urine testing was the least received component, similar to the results from another ANC survey in Uganda [37]. The low receipt of urine testing may be that it requires more technical expertise with a functional laboratory which may not be readily available at ANC facilities 
in these island communities [2], or that the facilities and/ or supplies for collecting urine are inadequate. Infrequent refresher training of providers and poor adherence to standards [43], may also have contributed. This undesirably affects diagnosis and management of hypertensive disorders of pregnancy, urinary tract infections and gestational diabetes in these remote communities, where prompt referrals to the mainland is a challenge for care not available on the islands. There is need to improve the provision of urine testing, to promptly manage pregnancy conditions and improve ANC quality.

A limitation of this study was the lack of comparison of self-reports to medical records as ANC attendance occurred from diverse locations. We were unable to visit ANC centers to assess health care provider perspectives, review stock outs, training, and ANC center-reported administration of the seven ANC components. Recall bias, a challenge with self-reports, was minimized using a shorter duration of recall ( 6 months) for most of the data we collected.

It is also possible that women who had complicated pregnancies led to over reporting of all ANC components receipt, as we did not assess the frequency of complicated pregnancies. Despite the limitations, these findings highlight crucial health services propositions for ANC in these islands.

\section{Conclusions}

The study shows that receipt of all ANC components was meagre in these islands FCs relative to the mainland. Wide differences existed between number of visits attended and receipt of all ANC components. Cost effective endeavors to improve components of care received by ANC attendees are urgently needed.

Task shifting of less technical components of care to CHWs may help improve receipt of all ANC components amidst critical shortages of skilled health workers in these island communities. Implementation programs should consider assessing components of care received by women attending ANC in these hard to reach FCs.

\section{Supplementary information}

Supplementary information accompanies this paper at https://doi.org/10. 1186/s12913-020-05739-9.

\section{Additional file 1.}

\section{Abbreviations}

AIC: Akaike's information criterion; ANC: Antenatal care; aOR: Adjusted odds ratio; BIC: Bayesian information criterion; CHW: Community health worker; Cl: Confidence interval; cOR: Crude odds ratio; eMTCT: Elimination of mother to child transmission of HIV; FCs: Fishing communities; FWA: Federal wide assurance; HIV: Human immunodeficiency virus; IAVI: International AIDS vaccine initiative; ICRH: International center for reproductive health; IPTp: Intermittent preventive treatment with sulphadoxine/pyrimethamine: ODK: Open data kit; OR: Odds ratio; SD: Standard deviation; STI: Sexually transmitted infection; UVRI: Uganda virus research institute; WHO: World health organization

\section{Acknowledgements}

We are grateful to the Uganda Virus Research Institute (UVRI) and UVRI-IAVI HIV Vaccine Program who provided administrative and institutional support.

\section{Authors' contributions}

AS, a PhD student, conceived the study, secured funding, training and coordination of field team, data management, cleaning, data analysis, interpretation of data and drafting of the manuscript. JN,GM,NN,JN, PN,HLK participated in data collection, data quality control, data management, modification, reviewing and approval of the manuscript. KC participated in the design, finalization of the protocol, reviewing progress, review and approval of manuscript. KP participated in the review, modification and approval of manuscript. KM participated in the review, modification and approval of manuscript. BB participated in conception of the idea, reviewing study progress, drafting, review and approval of manuscript. MP participated in the design, finalization of the protocol, reviewing progress, review and approval of manuscript. NK participated in conception of the idea, design of the study, reviewing study progress, drafting, review and approval of manuscript. OD participated in conception of the idea, design of the study, finalization of study protocol, reviewing study progress, data- analysis, interpretation of data, drafting, reviewing and approval of the manuscript. All authors substantially modified and approved the final manuscript prior to submission.

\section{Authors' information}

AS is a medical Doctor pursuing a PhD in Health Sciences at Ghent University. He also heads the Community Studies department at UVRI-IAVI HIV Vaccine Program Limited, Entebbe, Uganda.

JN,GM,NN,JN, PN and HLK are Research Assistants in the UVRI-IAVI HIV Vaccine Program's Community Studies department.

$\mathrm{KC}$ is a senior Medical Director at IAVI.

$\mathrm{KP}$ is Post-doctoral Assistant at International Centre for Reproductive Health $(\mathrm{ICRH})$ and Ghent university. She contributes to development of various grant proposals and to the Academic Network for Sexual and Reproductive Health Rights Policy.

KM is an Assistant Professor at ICRH and Ghent university in the field of global sexual and reproductive health, with a specific focus on sexual and reproductive health behavior, of adolescents and young people.

BB is a Senior Scientist and Lecturer with the department of Department of Immunology and Molecular Biology at Makerere University College of Health Sciences.

MP is the Director for Epidemiology at IAVI.

NK is an Infectious disease Epidemiologist, Professor and head of department Epidemiology and Biostatistics at Makerere University College of Health Sciences School of Public Health, Kampala, Uganda. He is also the

Director Makerere University Clinical Trials Unit.

$\mathrm{OD}$ is the Director of ICRH and Professor at Ghent University, Ghent Belgium. He coordinates research activities of a team of over 20 researchers divided in 3 sub teams studying sexually transmitted diseases; maternal and child health; and sexual and reproductive health among vulnerable populations.

\section{Funding}

This study was funded by the IAVI. IAVI's work is made possible by generous support from many donors including: The Bill \& Melinda Gates Foundation, the Ministry of Foreign Affairs of Denmark, Irish Aid, the Ministry of Finance of Japan in partnership with The World Bank, the Ministry of Foreign Affairs of the Netherlands, the Norwegian Agency for Development Cooperation (NORAD), the United Kingdom Department for International Development (DFID), and the United States Agency for International Development (USAID). The full list of IAVI donors is available at www.iavi.org.This study is made possible by the generous support of the American people through USAID. The components are the responsibility of IAVI and co-authors and do not necessarily reflect the views of USAID or the United States Government. IAVI also reviewed the study design, did not participate in collection, analysis or interpretation of data. IAVI participated in writing, reviewing and approval of the final manuscript 


\section{Availability of data and materials}

The dataset used and analyzed during the current study is readily available from the corresponding author upon reasonable request.

\section{Ethics approval and consent to participate}

The study and method of consent was approved by Uganda Virus Research Institute Research Ethics Committee [Federal Wide Assurance (FWA) number 00001354], reference number GC/127/17/09/622 and the Uganda National Council of Science and Technology (FWA number 00001293), reference number SS 4444. Women aged 18 years and above were enrolled after providing documented informed consent. Adolescents aged 13-17 years were enrolled after documented emancipated minor consent if they were emancipated minors or assent, with documented consent from their parents or guardians.

\section{Consent for publication}

Not applicable.

\section{Competing interests}

The authors declare that they have no competing interests.

\section{Author details}

'UVRI-IAVI HIV Vaccine Program, Entebbe, Uganda. ${ }^{2}$ Ghent University International Centre for Reproductive Health, Ghent, Belgium. ${ }^{3} \mathrm{IAVI}$, New York, NY, USA. ${ }^{4}$ Makerere University College of Health Sciences, Kampala, Uganda. ${ }^{5}$ Department of Epidemiology and Biostatistics, University of California at San Francisco, San Francisco, CA, USA.

Received: 29 March 2020 Accepted: 16 September 2020

Published online: 29 September 2020

\section{References}

1. Uganda Bureau of Statistics. Uganda Demographic and Health Survey 2016: Key Indicators Report [Internet]. Kampala; Uganda Bureau of Statistics; 2016. Available from: https://www.dhsprogram.com/pubs/pdf/FR333/FR333.pdf.

2. Uganda Ministry of Health. Annual health sector performamnce report [Internet]. Kampala: Ministry of Health Uganda; 2019. Available from: http:// library.health.go.ug/publications/performance-management/annual-healthsector-performance-report-20182019.

3. Thaddeus S, Maine D. Too far to walk: maternal mortality in context. Soc Sci Med. 1994;38(8):1091-110.

4. Say L, Chou D, Gemmill A, Tunçalp Ö, Moller A-B, Daniels J, et al. Global causes of maternal death: a WHO systematic analysis. Lancet Glob Heal. 2017;2(6):e323-33 Available from: http://www.thelancet.com/journals/ langlo/article/PIIS2214-109X(14)70227-X/fulltext.

5. Carroli G, Rooney C. How effective is antenatal care in preventing maternal mortality and serious morbidity? An overview of the evidence. Paediatr Perinat Epidemiol. 2001;15(Suppl. 1):1-42. https://onlinelibrary.wiley.com/ doi/10.1046/j.1365-3016.2001.0150s1001.X\#

6. Arunda M, Emmelin A, Asamoah BO. Effectiveness of antenatal care services in reducing neonatal mortality in Kenya: analysis of national survey data. Glob Health Action. 2017;10(1). Available from: https://doi.org/10.1080/ 16549716.2017 .1328796

7. Uganda Ministry of Health. Uganda Clinical Guidelines [Internet]. Kampala: Ministry of health Uganda; 2016. Available from: http://library.health.go.ug/ publications/guidelines/uganda-clinical-guidelines-2016.

8. World Health Organization. WHO recommendations on antenatal care for a positive pregnancy experience [Internet]. Geneva: World Health Organization; 2016. p. 152. [cited 2017 Jan 26]. Available from: http://www. who.int/nutrition/publications/guidelines/antenatalcare-pregnancy-positiveexperience/en.

9. Morón-Duarte LS, Ramirez Varela A, Segura O, Freitas da Silveira M. Quality assessment indicators in antenatal care worldwide: a systematic review. Int J Qual Heal care J Int Soc Qual Heal Care. 2019;31(7):497-505 Available from: https://www.ncbi.nlm.nih.gov/pubmed/30295805.

10. De Geyndt W. Managing the Quality of Health Care in Developing Countries [Internet]. World Bank Technical Papers. Washington, DC: The World Bank; 1995. p. 92. Available from: https://doi.org/10.1596/0-82133092-6.
11. Mwabu GM. Health care decisions at the household level: results of a rural health survey in Kenya. Soc Sci Med. 1986;22(3):315-9 Available from: http:// www.sciencedirect.com/science/article/pii/0277953686901292.

12. McCurdy RJ, Kjerulff KH, Zhu J. Prenatal care associated with reduction of neonatal mortality in Sub-Saharan Africa: evidence from Demographic and Health Surveys. Acta Obstet Gynecol Scand. 2011/05/27. 2011 ;90(7):779790. Available from: https://www.ncbi.nlm.nih.gov/pubmed/21426311.

13. Donabedian A, Wheeler JR, Wyszewianski L. Quality, cost, and health: an integrative model. Med Care. 1982;20(10):975-92 Available from: https:// pubmed.ncbi.nIm.nih.gov/6813605.

14. Turner K, Hameed AB. Hypertensive disorders in pregnancy current practice review. Curr Hypertens Rev. 2017;13(2):80-8.

15. Wingert A, Pillay J, Sebastianski M, Gates M, Featherstone R, Shave K, et al. Asymptomatic bacteriuria in pregnancy: systematic reviews of screening and treatment effectiveness and patient preferences. BMJ Open. 2019;9(3): e021347 Available from: https://bmjopen.bmj.com/content/bmjopen/9/3/ e021347.full.pdf.

16. Morroni $C$, Moodley J. The role of urine pregnancy testing in facilitating access to antenatal care and abortion services in South Africa: a crosssectional study. BMC Pregnancy Childbirth. 2006;6(1):26. Available from: https://doi.org/10.1186/1471-2393-6-26.

17. Haider BA, Olofin I, Wang M, Spiegelman D, Ezzati M, Fawzi WW. Anaemia, prenatal iron use, and risk of adverse pregnancy outcomes: systematic review and meta-analysis. BMJ. 2013 Jun;346:f3443.

18. Gomez GB, Kamb ML, Newman LM, Mark J, Hawkes SJ. Systematic reviews untreated maternal syphilis and adverse outcomes of pregnancy : a systematic review and meta-analysis maternal syphilis and adverse pregnancy outcomes. Bull World Health Organ. 2013;91(3):217-26.

19. Dunkelberg JC, Berkley EMF, Thiel KW, Leslie KK. Hepatitis B and C in pregnancy: a review and recommendations for care. J Perinatol. 2014;34(12): 882-891. Available from: https://doi.org/10.1038/jp.2014.167.

20. Calvert C, Ronsmans C. The contribution of HIV to pregnancy-related mortality: a systematic review and meta-analysis. AIDS. 2013;27(10):1631-9 Available from: https://www.ncbi.nlm.nih.gov/pubmed/23435296.

21. Drake AL, Wagner A, Richardson B, John-Stewart G. Incident HIV during pregnancy and postpartum and risk of mother-to-child HIV transmission: a systematic review and meta-analysis. PLOS Med. 2014;11(2):e1001608. Available from: https://doi.org/10.1371/journal.pmed.1001608.

22. Lagerberg RE. Malaria in pregnancy: a literature review. J Midwifery Womens Health. 2008:53(3):209-15 Available from: http://www.sciencedirect.com/ science/article/pii/S1526952308000743.

23. Mpairwe $\mathrm{H}$, Tweyongyere $\mathrm{R}$, Elliott $\mathrm{A}$. Pregnancy and helminth infections. Parasite Immunol. 2014;36(8):328-337. Available from: https://doi.org/10. 1111/pim.12101.

24. Pena-Rosas JP, De-Regil LM, Garcia-Casal MN, Dowswell T. Daily oral iron supplementation during pregnancy. Cochrane Database Syst Rev. 2015;7: CD004736.

25. World Health Organization. World health statistics 2019: Monitoring health for the SDGs, sustainable development goals. [Internet]. Geneva: World Health Organization; 2019. Available from: https:/www.who.int/gho/ publications/world_health_statistics/2019/en/.

26. Human Resources for Health Information System. National District Health Staff Records [Internet]. Vol. 5. 2017 p. 1-5 [cited 2017 Jun 18]. Available from: http://hris.health.go.ug/districts_manage/index.php/audit_summary_ districts?district=district\%7C101.

27. Henry L. Long road to good health services in Kalangala. Daily Monitor [Internet]. 2016 Jan 18; Available from: http://www.monitor.co.ug/ Magazines/HealthLiving/Long-road-good-health-services-Kalangala/689846-3 037214-bf5rp/index.html.

28. World Health Organization. World health statistics 2016: Monitoring health for the SDGs, sustainable development goals. [Internet]. Geneva: World Health Organization; 2016. [cited 2017 Feb 5]. Available from: https://www. who.int/gho/publications/world_health_statistics/2016/Annex_B/en/.

29. Uganda Bureau of Statistics. National population and housing census 2014 [Internet]. 2014. Available from: http://www.ubos.org/2016/03/24/census-2 014-final-results/.

30. The DHS Program Website. Funded by USAID. http://www.dhsprogram.com Accessed 18 July 2017.

31. Ssetaala A, Nabawanuka J, Matovu G, Nakiragga N, Namugga J, Nalubega P, et al. Antenatal care practices among hard-to-reach fishing communities on Lake Victoria: a community-based cross-sectional survey. J Prim Care 
Community Health. 2020;11:1-10. Available from: https://journals.sagepub. com/doi/https://doi.org/10.1177/2150132720923101.

32. StataCorp. Stata Statistical Software: Release 15 [Internet]. College Station, TX: StataCorp LLC; 2017. Available from: https://www.stata.com.

33. Shah A. ASDOC: Stata module to create high-quality tables in MS word from Stata output [Internet]. 2019. Available from: https://econpapers.repec. org/RePEc:boc:bocode:s458466.

34. Ratmann O, Kagaayi J, Hall M, Golubchick T, Kigozi G, Xi X, et al. Quantifying HIV transmission flow between high-prevalence hotspots and surrounding communities: a population-based study in Rakai, Uganda. Lancet HIV. 2020; 3018(19):1-11 Available from: https://www.sciencedirect.com/science/ article/pii/S2352301819303789?via\%3Dihub.

35. Droti B, O'Neill KP, Mathai M, Yao Tsidi Dovlo D, Robertson J. Poor availability of essential medicines for women and children threatens progress towards Sustainable Development Goal 3 in Africa. BMJ Glob Heal. 2019;4(Suppl 9):e001306 Available from: http://gh.bmj.com/content/4/ Suppl_9/e001306.abstract.

36. Arsenault C, Jordan K, Lee D, Dinsa G, Manzi F, Marchant T, et al. Equity in antenatal care quality: an analysis of 91 national household surveys. Lancet Glob Heal. 2018;6(11):e1186-95 Available from: http://www.sciencedirect. com/science/article/pii/S2214109X18303899.

37. Benova L, Dennis ML, Lange IL, Campbell OMR, Waiswa P, Haemmerli M, et al. Two decades of antenatal and delivery care in Uganda: a crosssectional study using demographic and health surveys. BMC Health Serv Res. 2018;18(1):1-15.

38. Fagbamigbe AF, Idemudia ES. Assessment of quality of antenatal care services in Nigeria: evidence from a population-based survey. Reprod Health. 2015;12(1):88. Available from: https://doi.org/10.1186/s12978-0150081-0.

39. Joshi C, Torvaldsen S, Hodgson R, Hayen A. Factors associated with the use and quality of antenatal care in Nepal: a population-based study using the demographic and health survey data. BMC Pregnancy Childbirth. 2014;14:94.

40. Benova L, Tuncalp O, Moran AC, Campbell OMR. Not just a number: examining coverage and content of antenatal care in low-income and middle-income countries. BMJ Glob Heal. 2018;3(2):e000779.

41. Carvajal-Aguirre L, Amouzou A, Mehra V, Ziqi M, Zaka N, Newby H. Gap between contact and content in maternal and newborn care: an analysis of data from 20 countries in sub-Saharan Africa. J Glob Health. 2017;7(2):1-8. https:/www.ncbi.nlm.nih.gov/pmc/articles/PMC5804037/.

42. Singh L, Dubey R, Singh S, Goel R, Nair S, Singh PK. Measuring quality of antenatal care: a secondary analysis of national survey data from India. BJOG An Int J Obstet Gynaecol. 2019;126(S4):7-13. Available from: https:// doi.org/10.1111/1471-0528.15825.

43. Chandler CIR, Kizito J, Taaka L, Nabirye C, Kayendeke M, Diliberto D, et al. Aspirations for quality health care in Uganda: how do we get there? Hum Resour Health. 2013 Mar;11:13.

\section{Publisher's Note}

Springer Nature remains neutral with regard to jurisdictional claims in published maps and institutional affiliations.

Ready to submit your research? Choose BMC and benefit from:

- fast, convenient online submission

- thorough peer review by experienced researchers in your field

- rapid publication on acceptance

- support for research data, including large and complex data types

- gold Open Access which fosters wider collaboration and increased citations

- maximum visibility for your research: over $100 \mathrm{M}$ website views per year

At $\mathrm{BMC}$, research is always in progress.

Learn more biomedcentral.com/submissions 